Jurnal Pemberdayaan: Publikasi Hasil Pengabdian kepada Masyarakat

Vol. 4, No. 3, Desember 2020, Hal. 291-296

ISSN: 2580-2569; e-ISSN: 2656-0542

DOI: https://doi.org/10.12928/jp.v4i3.1254

\title{
Pendampingan Implementasi Pembelajaran Matematika Berbasis Pendidikan Matematika Realistik dan High Order Thinking Skills
}

\author{
Vita Istihapsari, Aan Hendroanto \\ Universitas Ahmad Dahlan, Jalan Ringroad Selatan, Yogyakarta \\ Email: vita.istihapsari@pmat.uad.ac.id
}

\begin{abstract}
ABSTRAK
Guru matematika di Kabupaten Bantul, Yogyakarta, banyak yang mengalami kesulitan dalam menerapkan pembelajaran matematika berbasis Pendidikan Matematika Realistik (PMR) dan High Order Thinking Skills (HOTS). Banyak kendala yang dirasakan oleh guru sehingga perlu adanya pendampingan bagi guru dalam melaksanakan pembelajaran matematika berbasis PMR dan HOTS. Artikel ini mengulas tentang implementasi PMR dan HOTS pada kegiatan pembelajaran di kelas. Peserta pelatihan terdiri dari 54 guru dari 54 sekolah Muhammadiyah di Kabupaten Bantul. Implementasi dibagi menjadi 3 kelompok yaitu kelompok Timur, Barat, dan Selatan. Metode yang digunakan yaitu Lesson Study dalam kelompok beranggotakan 15-19 guru. Implementasi dilakukan sebanyak 3 kali di waktu yang berbeda dan sekolah yang berbeda pula. Hasil dari kegiatan ini yaitu para guru berhasil menyusun desain PMR dan HOTS yang diimplementasikan pada kegiatan pembelajaran matematika di kelas.
\end{abstract}

Kata kunci: Desain Pembelajaran, High Order Thinking Skills, Lesson Study, Pendidikan Matematika Realistik

\begin{abstract}
Mathematics teacher in Bantul Regency, Yogyakarta, many are having difficulty in applying mathematical learning in realistic mathematics education-based and HOTS. Many of the constraints felt by teachers so that the need for mentoring for teachers in implementing the learning of mathematics and mathematics education, discipline-based HOTS. This article is about the implementation of Realistic mathematics education and learning activities on the HOTS in the class. The participants consisted of 5454 teachers from school Muhammadiyah in Bantul Regency. The implementation was divided into 3 groups, namely the Group of East, West, and Center. Methods used namely Lesson Study in groups consisting of 10-15 teachers. Implementation is done by as much as 3 times in a different time and a different school anyway. The result of this activity, the teachers are able to make instructional design of mathematics learning activities implemented in mathematics in the classroom.
\end{abstract}

Keywords: High Order Thinking Skills, Instructional Design, Lesson Study, Realistic Mathematics Education

\section{PENDAHULUAN}

Peserta didik di tingkat Sekolah Dasar masih dalam kategori perkembangan kognitif di tahap konkret operasional. Menurut Piaget, anak pada tahap konkret sudah mampu berpikir penalaran untuk menyelesaikan suatu masalah yang konkret, namun bagaimanapun juga kemampuan berpikir mereka masih terbatas pada situasi nyata (Ibda, 2015). Hal ini menjadi tuntutan guru sekolah dasar untuk mengajarkan materi menggunakan alat peraga atau bendabenda konkret yang sering dijumpai oleh peserta didik dalam kehidupan sehari-hari. Dengan demikian, guru tidak disarankan untuk membelajarkan materi secara abstrak.

Berdasarkan diskusi bersama guru-guru kelas Sekolah Dasar Muhammadiyah Kabupaten Bantul, diperoleh fakta bahwa guru masih menggunakan metode pembelajaran konvensional dimana guru menjelaskan dan peserta didik hanya mendengarkan penjelasan guru serta 
mencatat yang dituliskan guru di papan tulis. Hal ini mengakibatkan kesulitan pada peserta didik dalam memahami konsep materi yang diajarkan oleh guru khususnya pada mata pelajaran matematika.

Mata pelajaran matematika merupakan mata pelajaran yang penting, menjadi dasar keterampilan berpikir kritis, logis dan kreatif yang harus dikembangkan sejak dini (Amir, 2015). Pembelajaran matematika yang dilaksanakan secara abstrak berpotensi membuat peserta didik merasa bahwa matematika tidak bermanfaat dalam kehidupan sehari-hari, tidak bermakna dan membuat peserta didik takut belajar matematika (Untari, 2013).

Dalam pembelajaran matematika di kenal dengan pembelajaran matematika realistik. Pembelajaran realistik dalam matematika merupakan konsep pembelajaran yang membantu para guru mengaitkan antara materi pelajaran matematika dan situasi-situasi dunia nyata atau dunia yang disimulasikan, dan memotivasi para siswa mengaitkan matematika dan kehidupan sehari-harinya (Freudenthal, 1991; Istiandaru et. al., 2015). Pembelajaran matematika realistik beranggapan bahwa peserta didik datang ke ruang kelas dengan otak yang tidak kosong dimana mereka sudah mempunyai pengetahuan sebelumnya dan pengetahuan yang akan dipelajari bukan merupakan hal yang sudah jadi, melainkan peserta didik harus mengkontruksi sendiri berdasarkan atas pengetahuan yang sudah dimiliki sebelumnya (Gravemeijer et.al., 2003).

Tujuan pembelajaran matematika realistik adalah peserta didik mempunyai pengetahuan yang dapat ditransfer dari satu masalah ke masalah lain dan dari konteks satu ke konteks lain. Pengunaan konteks dalam hal ini dinamakan didactical phenomenology (Freudenthal, 1986; Gravemeijer \& Terwel, 2000; Van den Heuvel-Panhuizen, 2014; Hendroanto, 2018). Tujuan tersebut akan dapat dicapai apabila pembelajarannya menggunakan pembelajaran matematika realistic dan peserta didik belajar dengan cara menaruh materi pelajaran dalam konteks yang bermakna. Dalam pandangan Freudenthal (1991), agar matematika memiliki nilai kemanusiaan maka pembelajarannya haruslah dikaitkan dengan realita, dekat dengan pengalaman anak serta relevan untuk kehidupan masyarakat.

Tuntutan Kurikulum 2013 terhadap pembelajaran matematika adalah menjadikan peserta didik untuk berpikir kreatif, kritis, komunikatif, kolaboratif (Hidayati, 2017). Untuk memenuhi tuntutan tersebut salah satu cara yang dapat dilakukan adalah dengan pembelajaran High Order Thinking Skills (HOTS). Pembelajaran HOTS mengembangkan kemampuan berpikir dan bernalar untuk menjawab pertanyaan yang rumit dan atau memecahkan suatu kasus atau masalah. Dalam Taxonomy Bloom, terdapat enam tingkatan berpikir yaitu Mengingat (Level C1), Memahami (Level C2), Menerapkan (Level C3), Menganalisis (Level C4), Evaluasi (Level C5), Mengkreasi (Level C6) (Bloom et.al., 1984). Keenam level berpikir ini harus terintegrasi dalam pembelajaran sehingga tujuan dari kurikulum 2013 dapat tercapai. Namun, terdapat beberapa kesulitan yang ditemu guru dalam penerapan HOTS ini di dalam kelas, khususnya guru Sekolah Dasar.

Guru di Sekolah Dasar Muhammadiyah Bantul yang mengampu mata pelajaran matematika memiliki latarbelakang pendidikan yang beragam seperti lulusan PAI, Bahasa Indonesia, PPKn dan lainnya. Berbagai macam latar belakang guru tersebut menjadi salah satu kesulitan guru dalam menyampaikan mata pelajaran matematika. Guru cenderung menyampaikan mata pelajaran matematika sebatas dari buku guru, tanpa mengembangkannya agar sesuai dengan perkembangan kognitif peserta didik. Oleh karena itu guru membutuhkan pelatihan untuk merancang dan mengimplementasikan pembelajaran berbasis pendidikan matematika realistik dan HOTS. Pelatihan dirancang dalam tiga kegiatan yaitu pelatihan, workshop, dan pendampingan. Artikel ini fokus kepada kegiatan pendampingan.

\section{METODE}

Peserta pelatihan terdiri dari 54 guru dari 54 SD Muhammadiyah se-Bantul. Materi yang diberikan kepada peserta adalah pelatihan mengenai pembelajaran berbasis pendidikan 
matematika realistik dan pembelajaran HOTS. Pengabdian ini terdiri dari 3 kegiatan, dimulai dari pelatihan, workshop, dan pendampingan langsung ke sekolah. Kegiatan pendampingan dilakukan dengan membagi 54 guru kedalam 3 wilayah yaitu wilayah barat, wilayah timur, dan wilayah selatan.

Pembahasan pengabdian ini fokus pada kegiatan pendampingan yang diadakan di SD Unggulan Aisyiyah, SD Muhammadiyah Bodon, dan SD Muhammadiyah Jogodayoh. Kegiatan di kemas dalam bentuk Lesson Study, sehingga hanya ada 1 guru model dan 15-18 guru lainnya sebagai observer. Sebelumnya, kelompok masing-masing wilayah sudah menyusun RPP dengan model pembelajaran realistik dan HOTS.

Seluruh peserta pelatihan yang berjumlah 54 sebelumnya sudah diberikan pelatihan di Gedung Dakwah PDM Bantul mengenai pembelajaran matematika berbasis Pendidikan Matematika Realistik (PMR) dan HOTS. Kemudian mereka dapat kesempatan untuk workshop membuat desain pembelajaran. Setelah mereka melakukan dua kegiatan tersebut, peserta diarahkan untuk menyusun pembelajaran berbasis PMR dan HOTS yang akan diimplementasikan ke dalam pembelajaran, dimana salah seorang guru model akan dipilih untuk memberikan pembelajaran berbasis PMR dan HOTS di sekolahnya. Seluruh peserta dibagi dalam 3 kelompok wilayah, yaitu wilayah barat, timur dan selatan. Kemudian setiap kelompok diminta untuk berdiskusi menentukan ketua kelompok, waktu pendampingan, guru model, dan model pembelajaran berbasis PMR yang didalamnya nanti juga ada pembelajaran HOTS. Hasil pembagian kelompok dapat dilihat pada Tabel 1.

Tabel 1. Jadwal Pendampingan

\begin{tabular}{lllcl}
\hline Wilayah & \multicolumn{1}{c}{ Nama SD } & \multicolumn{1}{c}{ Hari, tanggal } & Waktu & Materi \\
\hline Barat & SDU Aisyiyah & Rabu, 31 Juli 2019 & $12.30-16.00$ & Pecahan \\
\hline Timur & SD Muh. Bodon & Rabu, 7 Agustus 2019 & $07.30-11.00$ & Pecahan \\
\hline Selatan & SD Muh. Jogodayoh & Selasa, 20 Agustus 2019 & $07.30-11.00$ & Pecahan \\
\hline
\end{tabular}

\section{HASIL, PEMBAHASAN, DAN DAMPAK}

Kegiatan pendampingan pertama kali diadakan di wilayah barat yaitu di SD Unggulan Aisyiyah pada hari Rabu, 31 Juli 2019 dengan guru model bernama Budi Gunawan. Tahap persiapan diadakan untuk menyamakan persepsi dari 18 guru untuk pembelajaran di kelas nantinya. Dalam tahap persiapan ini dihadiri oleh Bapak Kepala Sekolah, dan 1 perwakilan dari PDM yaitu Bapak Herman. Kepala Sekolah mendukung adanya kegiatan ini, karena kegiatan ini bisa menjadi awal kegiatan di sekolah, dan sekolah bisa mengembangkannya kelak. Kelompok ini sudah menyiapkan Rencana Pelaksanaan Pembelajaran dan gunung es yang merupakan desain pembelajaran PMR dimana didalamnya terdapat HOTS. Saat pembelajaran, peserta didik sangat antusias diawal pembelajaran, namun diakhir pembelajaran peserta didik kurang terkondisikan. Desain pembelajaran PMR sudah dilakukan namun kurang dalam hal media pembelajaran. Media pembelajaran diperlukan untuk mengarahkan peserta didik dari bentuk nyata ke bentuk abstrak pecahan. Pembelajaran HOTS juga sudah ada dalam RPP dan desain pembelajaran. Setelah pembelajaran selesai, seluruh peserta melakukan refleksi terhadap peserta didik, desain pembelajaran PMR dan HOTS.

Kegiatan pendampingan kedua diadakan di wilayah Timur yaitu di SD Muhammadiyah Bodon pada hari Rabu, 7 Agustus 2019 dengan guru model bernama Nurul M. Tahap persiapan dihadiri oleh 15 guru lainnya, dan Kepala Sekolah guna melakukan persiapan pada pembelajaran yang akan dilaksanakan. Kelompok ini sudah membuat Rencana Pelaksanaan Pembelajaran (RPP), gunung es sebagai desain pembelajaran PMR dan HOTS. Pembelajaran berlangsung tidak jauh dari RPP yang dibuat oleh kelompok. Dalam pembelajaran pun 
berlangsung sesuai dengan desain pembelajaran PMR dan HOTS. Setelah pembelajaran usai, peserta melakukan refleksi.

Kegiatan pendampingan ketiga diadakan di wilayah selatan yaitu di SD Muhammadiyah Jogodayoh pada hari Selasa 20 Agustus 2019 dengan guru model bernama Ana Pratiwi. Kegiatan persiapan dihadiri oleh 19 guru, Kepala Sekolah SD Muhammadiyah Jogodayoh, serta perwakilan dari PDM. Kelompok sudah mempersiapkan desain pembelajaran gunung es PMR dan HOTS sebagaimana diilustrasikan pada Gambar 1.

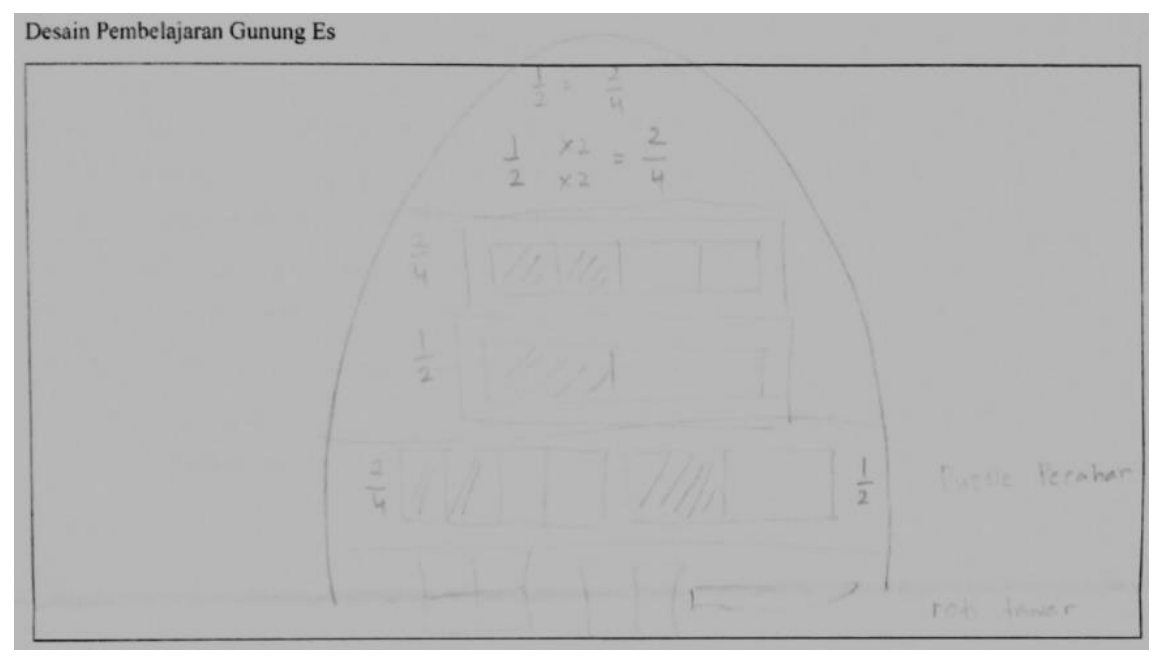

Gambar 1. Desain Pembelajaran Gunung Es Materi Pecahan Senilai

Pada Gambar 1, guru merancang desain pembelajaran dalam 4 level dari konkret ke abstrak. Pada level pertama guru menggunakan media pembelajaran berupa roti tawar. Roti tawar tersebut diberikan ke peserta didik kemudian diminta untuk membagi roti ke teman sekelompoknya sama besar. Kegiatan ini merupakan awal dari desain PMR yaitu peserta didik dikenalkan terlebih dahulu benda konkrit yang sering ditemui peserta didik pada kehidupan sehari-hari.

Pada level 2, guru menggunakan media pembelajaran berupa puzzle pecahan yang berbentuk kotak-kotak dari gabus yang telah dibagi-bagi sehingga bisa diambil oleh peserta didik sebagaimana diilustrasikan pada Gambar 2. Pada tahap ini guru meminta peserta didik untuk bergantian maju ke depan kelas untuk mencoba menyatakan pecahan senilai menggunakan alat peraga puzzle pecahan tersebut.

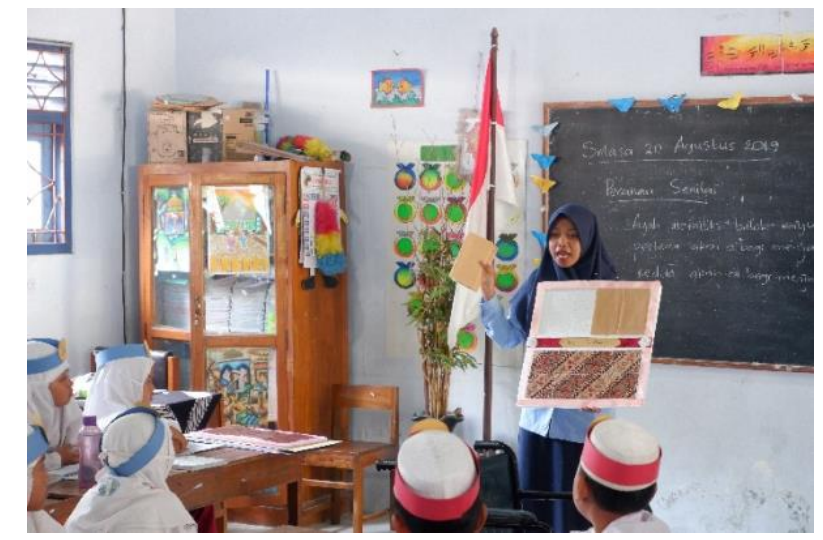

Gambar 2. Guru menggunakan alat peraga berupa puzzle pecahan untuk mengarahkan peserta didik dari benda konkrit ke abstrak 
Pada level 3, guru mengarahkan peserta didik dari berpikir konkret ke abstrak mengenai pecahan senilai dengan menggunakan gambar di papan tulis. Guru berhasil memindahkan ilustrasi dari semula puzzle pecahan ke bentuk gambar di papan tulis. Pada level inilah tahapan abstrak peserta didik dimulai.

Pada level 4, guru membelajarkan pecahan senilai menggunakan symbol-simbol matematika. Di papan tulis sudah tidak ada lagi gambar, melainkan perhitungan-perhitungan pecahan senilai. Runtutan desain pembelajaran ini sudah sesuai dengan PMR dan HOTS. Peserta didik juga sangat antusias dengan penggunaan media pembelajaran tersebut. Kegiatan dilanjutkan dengan kegiatan refleksi, dimana setiap guru mengutarakan refleksi pembelajaran yang telah berlangsung.

Secara umum, implementasi desain pembelajaran yang telah dibuat berjalan dengan lancer dan tidak ditemui banyak kendala yang berarti. Guru dalam melakukan aktivitas bersama siswa sudah baik dan sesuai dengan yang diinginkan. Namun, aktivitas yang dikembangkan ini masih pendek dan belum mencakup semua materi yang ada. Oleh karena itu, diharapkan guru dapat terus mengimplementasikan dan membuat desain-desain baru untuk topik-topik yang lain.

\section{SIMPULAN}

Melalui pendampingan penyusunan desain pembelajaran PMR dan HOTS, guru berhasil merancang dan mengimplementasikan desain pembelajaran gunung es dalam 4 level pada pembelajaran matematika dengan materi pecahan senilai, yaitu level 1 pembelajaran menggunakan benda konkret berupa roti tawar yang dibagi rata ke teman-teman sekelompok, level 2 menggunakan model puzzle yang merepresentasikan pecahan senilai, level 3 menggunakan gambar ilustrasi.

\section{UCAPAN TERIMAKASIH}

Tim pengusung kegiatan pengabdian kepada masyarakat menyampaikan terima kasih kepada LPPM UAD yang telah mendanai kegiatan pengabdian ini melalui skema pengabdian reguler. Tim juga berterima kasih kepada para guru sekolah dasar Muhammadiyah di Kabupaten Bantul yang telah mengikuti kegiatan dengan baik.

\section{DAFTAR PUSTAKA}

Amir, M. F. (2015). Proses berpikir kritis siswa sekolah dasar dalam memecahkan masalah berbentuk soal cerita matematika berdasarkan gaya belajar. JURNAL MATH EDUCATOR NUSANTARA: Wahana Publikasi Karya Tulis Ilmiah di Bidang Pendidikan Matematika, 1(2), 159-170.

Bloom, B. S., Krathwohl, D. R., \& Masia, B. B. (1984). Bloom taxonomy of educational objectives. Allyn and Bacon, Boston, MA. Copyright (c) by Pearson Education.< http://www. coun. uvic. ca/learn/program/hndouts/bloom. html.

Freudenthal, H. (1986). Didactical phenomenology of mathematical structures (Vol. 1). Springer Science \& Business Media.

Freudenthal, H. (1991). Revisiting Mathematics Education: China Lectures. New York: Kluwer Academic Publishers.

Gravemeijer, K., \& Terwel, J. (2000). Hans Freudenthal: a mathematician on didactics and curriculum theory. Journal of curriculum studies, 32(6), 777-796.

Gravemeijer, K., Bowers, J., \& Stephan, M. (2003). Chapter 4: A Hypothetical Learning Trajectory on Measurement and Flexible Arithmetic. Journal for Research in Mathematics Education. Monograph, 51-66. 
Hendroanto, A. (2018). Didactical Phenomenology Untuk Mengembangkan Aktivitas Pembelajaran Geometri Bidang Dengan Pendekatan Pendidikan Matematika Realistik. In Prosiding Seminar Nasional Pendidikan Matematika Etnomatnesia.

Hidayati, A. U. (2017). Melatih keterampilan berpikir tingkat tinggi dalam pembelajaran matematika pada siswa sekolah dasar. Terampil: Jurnal Pendidikan dan Pembelajaran Dasar, 4(2), 143-156.

Ibda, F. (2015). Perkembangan kognitif: teori jean piaget. Intelektualita, 3(1), 27-38.

Istiandaru, A., Istihapsari, V., Wardono, W., \& Mulyono, M. (2015). Problem Based Learning (PBL) Dengan Pendekatan Realistik-Saintifik dan Asesmen Pisa Untuk Meningkatkan Kemampuan Literasi Matematika. Edumatica: Jurnal Pendidikan Matematika, 5(01), 111.

Untari, E. (2013). Diagnosis kesulitan belajar pokok bahasan pecahan pada siswa kelas V sekolah dasar. Jurnal Ilmiah STKIP PGRI Ngawi, 13(1), 1-8.

Van den Heuvel-Panhuizen, M. (2014). Didactical Phenomenology (Freudenthal). Encyclopedia of mathematics education, 174-176. 